\title{
Integration of Displaced Syrians in Saudi Arabia
}

\author{
Emina Osmandzikovic ${ }^{ \pm}$
}

\begin{abstract}
The integration of displaced populations is primarily measured in singular variables. The focus mostly is on economic self-sufficiency or citizenship acquisition. The overall underperformance of the traditional relationship between displaced populations and their host-countries has given birth to a plethora of novel approaches. The idea is to reconcile the host-countries' geo-economic interests with the needs of the displaced populations. This is also the case in some countries that are not signatories to the 1951 Refugee Convention and the 1967 Protocol, such as Nigeria, Malaysia, and Saudi Arabia. These countries have tried to integrate displaced populations in their national agendas, albeit with little input from the beneficiaries of such programs. As a non-signatory of the 1951 Refugee Convention, Saudi Arabia developed an alternative approach to the integration of displaced Syrians. It has demonstrated a wide area of coverage and adaptability, covering legal status, education, healthcare, employment, and social integration. This article provides an analysis of the government refugee programs, juxtaposed to topic modelling of semi-structured interviews conducted with displaced Syrians $(n=21)$ within the Kingdom. The findings illustrate that, despite the comprehensive nature of the Saudi approach, which ensures socio-economic independence for displaced Syrians, the integration process from the viewpoint of the displaced populations suggest that integration remains a highly subjective and personal process.
\end{abstract}

Keywords: refugees; displacement; migration; accommodation; reception; integration; Saudi Arabia; Syrians.

\section{Introduction}

States Parties to the 1951 Convention and the 1967 Protocol on the Status of Refugees (hereafter referred to as the "1951 Convention") have the primary obligation to displaced persons for the reception and provision of necessary support for those seeking asylum for as long as the individuals in question are present in the State (UNHCR, 1951). Under this Convention, the States Parties are at the forefront when it comes to safeguarding the displaced populations. Both the 1951 Convention and the 1967 Protocol relating to the Status of Refugees, affirm that refugees have the right to be provided by their host-countries, with active and informed participation of host-communities.

In its original mandate, the 1951 Convention supported the self-reliance of displaced populations, thus ensuring that host countries, including host communities, are their primary bearers. In Europe, a place of refuge to more than a million Syrians, the 1951 Convention signatory

\footnotetext{
${ }^{ \pm}$Emina Osmandzikovic, TRENDS Research, United Arab Emirates. E-mail: eminaosmandzik@gmail.com.
}

Acknowledgements: I would, hereby, like to extend deep gratitude to the Riyadh-based King Faisal Center for Research and Islamic Studies (KFCRIS) in addition to the Abu Dhabi-based TRENDS Research and Advisory, as my fieldwork in Saudi Arabia has been generously assisted by both institutions. I would also like to thank Ehtesham Shahid for generously editing this paper. 


\section{Integration of Displaced Syrians in Saudi Arabia}

countries have faced numerous constraints in processing an unprecedented number of asylum applications in the midst of the "refugee crisis" (Holmes and Castaneda, 2016).

This is due to an over-reliance on the UNHCR to handle initial reception and resettlement and an absence of political will to accept Syrian refugees. The role of the UNHCR is supposed to be supportive of the States Parties in receiving displaced persons but States have deferred responsibility for both reception and settlement. As a result, displacement has become a semi-permanent status for many as early as in 2000 as they cannot be seen as a temporary issue that can be quickly resolved (UNHCR, 2000, p. 22). The most evident example is 5.6 million Syrians forced out of the country by an armed conflict that shows no signs of ending.

In relation to the current views on migration and integration in official policy-making circles, there is a prevalent perception of refugees and asylees as economic migrants and a security threat. This is making addressing the refugee crises adequately difficult. This has resulted in the absence of a connection between the 1951 Convention and the reality of displacement. Congruently, with the unprecedented and exponentially increasing number of asylum applications, it has become more exigent to implement, in an efficient manner, systems for the reception so that displaced persons and communities can gain the security of certainty allowing them to start rebuilding their lives.

The international community, especially countries party to the 1951 Convention, has shown a lack of political will in helping displaced persons, which has contributed to continued insecurity. They have also failed in finding creative solutions to resolve the crisis. It has become pertinent for several countries, including non-signatories of the 1951 Convention, to seek out alternative approaches to the reception and integration of displaced persons to meet the challenges facing the world today, particularly approaches that are indigenous and context-specific while supportive of human security and dignity.

In this study, integration of displaced populations ${ }^{1}$ has been measured with singular variables, in most cases, focusing on economic self-sufficiency or citizenship acquisition (Bevelander and Lundh, 2007; Bloch, 2008; Valenta and Bunar, 2010; Bansak et al., 2018).

Considering the ongoing situation in the Syrian Arab Republic, the Republic of the Union of Myanmar, and the Bolivarian Republic of Venezuela, the most recent refugee crises have demonstrated the need to rethink traditional approaches to displacement and reception. The situation also calls for more locally-based and context-specific approaches as originally envisaged by the 1951 Convention. The existing approaches to protracted displacement and eventual integration tend to be inefficient, unsustainable, and lead to the dependency of vulnerable populations on systems that might not understand their needs (Von Buchwald, 1994; Harvey and Lind, 2005; Betts and Collier, 2015; Aleinikoff, 2015).

Therefore, it is critical to ascertain that the locally-based and context-specific approach to the integration of displaced populations is not an original patent of the Syrian refugee crisis. A humanitarian response designed for the short-term too often ends up administering long-term dependency and a lack of unified agency in accessing sustained livelihoods, as many refugees and migrants end up in protracted displacement.

\footnotetext{
${ }^{1}$ Persons of concern to the United Nations High Commissioner for Refugees (UNHCR), refer to as displaced populations in the paper, encompass internally displaced persons, refugees, asylum-seekers, migrants, stateless people, unaccompanied minors, and minorities and other groups at risk.
} 
As for utilising an appropriate definition of the integration process in this paper, given the absence of consensus within the literature, the term is mainly understood as "a process of mutual adaptation between a host-state and displaced populations" (Arnaout, 1986). However, the essence of this deeply complex process varies from country to country. While naturalisation may be pertinent to greater integration (Hainmueller, Hangartner, and Peitrantuono, 2015) in a particular context, the grey area of the process itself that goes beyond naturalisation is yet to be wholly-tackled by literature.

In a number of countries not a signatory to the 1951 Refugee Convention and the 1967 Protocol, including virtually all countries belonging to the Arab League, integration does not imply obtaining citizenship and is, therefore, not included in the overall evaluation of the integration process in this article. According to the United Nations High Commissioner for Refugees (UNHCR), a protracted refugee situation is one in which 25,000 or more refugees from the same nationality have been in exile for five consecutive years, or more, in a given host country (UNHCR, 2019).

Based on the existing definition and the latest UNHCR report,15.9 million refugees found themselves in a situation of protracted displacement in late 2018. This represented 78 per cent of all refugees, compared with 66 per cent in 2017. Of this number, 5.8 million were in a situation lasting 20 years or more, dominated especially by the 2.4 million Afghan refugees in the Islamic Republic of Iran and Pakistan where the displacement of populations has continued 40 years (UNHCR, 2019). As per the latest figures, no protracted situation was resolved in 2018.

\section{Displaced Syrians in Saudi Arabia}

The traditional approach to forced migration would be to tackle the issue of refugees and economic migrants separately concerning the 1951 Convention (UNHCR, 1951). However, the case of displaced Syrians in Saudi Arabia does not comply with the theoretical prediction of the state's behaviour in response to a massive influx of displaced populations. It doesn't reflect the displaced populations' changing perception towards the greater socio-economic condition of the protracted displacement.

Despite not being a signatory to the 1951 Convention, the Kingdom of Saudi Arabia has diligently worked to amend its traditional immigration and integration system since 2011. It has developed a comprehensive program of acceptance of displaced populations from war-torn countries, with a special focus on displaced Syrians since 2011, later on encompassing displaced Yemenis in 2015. The revision and modification of the integration system for non-nationals to accommodate displaced Syrians is an unprecedented step towards creating a novel approach that fits the particular context of the host country. It also improves the perception of the displaced populations on their socio-economic condition in the host-society.

Contrary to the global consensus, this approach in a non-signatory state encourages the selfreliance of displaced populations in a localised and context-specific dimension. Given the depth of inquiry and the wealth of data obtained during my fieldwork in Saudi Arabia, this article aims to analyse a novel system of reception and integration of displaced populations. The study is complemented by an examination of their perception of the integration process and the state of their displacement. 


\section{Integration of Displaced Syrians in Saudi Arabia}

This article discusses the integration process from the viewpoint of displaced Syrians in a nonsignatory country of the 1951 Convention; namely, Saudi Arabia, as juxtaposed to the official integration measures implemented to counter potential dependency of the displaced populations within the country. It attempts to approach the integration experience of displaced populations more comprehensively while highlighting official policies put in place to encourage their self-reliance.

\section{Brief literature review}

There is a jarring deficit of research that examines the socio-economic lives of displaced populations. The literature mainly focuses on the economic impact of displaced populations on the host-country (Betts and Collier, 2015; Bakker, Dagevos, and Engbersen, 2014; Dimitrov and Angelov, 2017) tangible outcomes of integration, such as legal aspects of asylum and integration (Barou, 2014) or rates of inter-marriage with the domicile populations (Gonzales-Ferrer et al., 2018). Moreover, refugees are almost always studied with distinct parameters and not examined as a sub-group of migrants who might fall under similar economic categories, which both the academic literature and government policies reflect.

Taking into account the unorthodox Saudi approach to displaced Syrians, this article lays out the spectrum of potential responses of refugee reception and accommodation that delineate bad from good host-states. In her article on factors influencing the policy responses of host governments to massive refugee influxes, Jacobsen analysed a spectrum of available responses to a refugee crisis, ranging from 'perfect compliance' to 'perfect non-compliance' (2002) (please see Appendix Figure 1).

In the occurrence of a large refugee influx, a host-government can choose to do nothing, respond positively, or respond negatively, a decision that is intimately dictated by various factors: (i) bureaucratic choices made by the host-government, (ii) international relations, (iii) absorption capacity of the local host-community, and (iv) national security considerations. However, this range of responses ceases to be relevant for policy-making and the decision of receiving displaced populations once the host-state signs and ratifies the 1951 Convention and the 1967 Protocol. Many states, however, do not neatly fit into the policy spectrum, especially the non-signatories of the 1951 Convention and the 1967 Protocol. For instance, Arnaout points out that the constitutions of most of the Arab countries contain provisions guaranteeing the right of asylum, and some Arab countries; namely, Iraq, Lebanon, Sudan, promulgate laws granting asylum to foreigners (1986).

Not all Arab countries, however, have acceded to international refugee conventions or ratified them. According to a study on refugee benefits to state resources by Karen Jacobsen, there is great human capital to be tapped into in the form of refugee labour, skills, and entrepreneurship to further and expand the economy (Jacobsen, 2002). Herein, social and political resources, or 'refugee resources,' as Jacobsen names them, potentially represent an important state-building contribution for the refugee-hosting state.

These resources can, in turn, help develop particular economic sectors, increase welfare for the local population, and potentially extend the bureaucratic reach of the state. Refugees can have a multiplier effect by expanding the capacity and productivity of the receiving area's economy through local and even regional trade and growth of markets (2002). This, however, comes with a caveat. Jacobsen conducted her study in three African countries where the majority of refugee populations have been settled in camps, and camp proliferation and greater economic incorporation of refugees has emerged as a fairly recent phenomenon. 
In the particular case of Syrian refugees, Alexander Betts and Paul Collier produced a report on the potential benefits of the economic participation of Syrian refugees in the local markets of their host countries (Betts and Collier, 2015). International policy toward the Syrian refugee crisis is both antiquated and fuelled by panic. According to Betts and Collier, it is premised on the same logic that has characterised refugee policies around the world since the mid-1950s, wherein donors write cheques to support humanitarian relief efforts and countries that receive and host refugees are expected to take care of them, often in a (closed) camp setting.

In regard to the 2015 refugee crisis that originated in the Middle East and North Africa (MENA) region and spilt over into Europe as well, the sense of panic has come from the sheer magnitude of the refugee inflow, without any regard or knowledge of history. Historically, however, a number of states in Europe and beyond have successfully employed refugees in the service of domestic economic development, to the benefit of both the displaced and the host societies. One prominent example is the case of Greece in the 1920s.

The League of Nations High Commissioner for Refugees worked with the International Labor Organization (ILO) to integrate 1.5 million Greek refugees who had fled Turkey for their ethnic homeland. With loans from the League of Nations, the government employed refugees in the process of economic transformation of underdeveloped regions. The effects on the economy were striking: primitive farming practices were replaced with modern ones, and refugees improved their host-states (2015), albeit in agricultural, rather than industrial, development.

Literature seems to suggest that the collapse of the traditional relationship between host states and refugee populations calls for a new policy, both in the economic and in the political realm. Such a policy has to be financially sustainable and must reconcile the interests of host states with the needs of the displaced. State-assisted programmes for economic integration of displaced populations into the local labour market is increasingly being seen as the best way forward.

Displaced populations need the opportunity to eliminate system dependency, and this can only be provided if they are integrated into the economy for the duration of their refuge. In their study on refugees' impact on the economies of the European Union member states, Dimitrov and Angelov argue that without a thorough analysis of the specifics of the local economy of the refugees' hostcountry in a transparent way in the accommodation and eventual integration of refugees, not much success will be made while the existing socio-economic challenges will persist and worsen (Dimitrov and Angelov, 2017).

In the absence of other relevant literature, while Dimitrov and Angelov base their study in the $\mathrm{EU}$, this article follows the same principle in examining the localised and context-specific characteristics of the Saudi approach to displaced populations. The approach of political scientists predominantly utilises case studies and interviews that prefer engaging with officials (Valenta and Thorshaug 2013; Mayblin, 2017) rather than the displaced populations. The distinguishing aspect of this article is the voice of the displaced populations that is at the forefront of the argument, situated in the greater context of a non-signatory country of the 1951 Refugee Convention; namely, Saudi Arabia. Most studies fail to analyse integration from the viewpoint of displaced populations, especially given its complexity (Osmandzikovic, 2017; Osmandzikovic, 2019a).

A brief assessment of existing studies in the previous section suggests that multiple factors affect the perception of displaced populations on the integration process with great contestations on 


\section{Integration of Displaced Syrians in Saudi Arabia}

the extent to which these factors overlap. Integration is a complex process and is one reason why it has no single and universally-applied definition. According to the Council of the European Union, integration is a two-way process, dynamic (Council of the European Union, 1990). On a community-wide, rather than individual level, there are three broad and partly overlapping spheres of integration in literature. They include social, political, and economic integration into host societies (Carens, 2005; Huddleston, Niessen, and Tjaden, 2012; Dancygier and Laitin, 2014; Castles, 2013; OECD, 2012). In short, the literature identifies a plethora of factors associated with integration.

As the subject of this article, displaced Syrians are those who have come to Saudi Arabia post2011 on a visit visa and are officially referred to as Syrian visitors. As of December 2018, 673,669 Syrian visitors were residing in Saudi Arabia, with 2,570,972 renewals of visit visas from 2011 until the beginning of 2019 (Osmandzikovic, 2019b).

\section{Data and Method}

Regarding the topic modelling of interviews, conducted with displaced Syrians in Saudi Arabia, I use textual analysis based on word co-occurrences and topic modelling in " $\mathrm{R}$ ", as based on a novel approach to qualitative data analysis (Welbers, Van Atteveldt, and Benoit, 2017). Given the novelty of the approach to the perception of displaced populations on their reception and accommodation in a non-signatory country of the 1951 Refugee Convention and the 1967 Protocol, I conduct unsupervised machine learning. I generate code for recognising the most commonly occurring patterns of words in interviews with displaced Syrians, subsequently clustering them around several software-identified themes, which is explained in the following sections of the article.

This article utilises a mixed-methods approach to understand the alternative to reception and accommodation of displaced populations in non-signatory countries of the 1951 Refugee Convention and the 1967 Protocol; namely, Saudi Arabia, in addition to tackling the socio-economic perception of displaced Syrians within the Kingdom on their situation. Given the paucity within the existing literature (McKim, 2015), the use of mixed-methods as a combination of semi-structured interviews, archival work and topic modelling of interview transcript gives a novel and broader understanding of the phenomenon. To that extent, this article adds value to the existing literature by promoting further knowledge creation (Hurmerinta-Peltomäki and Nummela, 2006).

\section{Comprehensive official policy overview}

Due to a lack of publicly available data on displaced Syrians in Saudi Arabia, I attempted to directly engage with and reach out to government representatives in charge of immigration via inperson interviews. The principal method of data collection consisted of recorded meetings with representatives of various government offices and the private sector. Over three months (JanuaryMarch 2019), I conducted 10 interviews to compile information and data, and produce a comprehensive framework of the Saudi approach to receiving and accommodating displaced populations. These interviews are separate from the interviews done with the displaced Syrians. They were primarily conducted with state officials in several ministries (please see Appendix) to provide a comprehensive and official overview of the Saudi integration system.

Through my interviews, I also intended to encompass stakeholders who are relevant in devising policy recommendations for integration. Overall, I have compiled more than 10 hours of recorded 
material on the reception of and integration efforts for Syrians. Most interviews were conducted on a one-to-one basis. Interviews with government stakeholders are not included in topic modelling but form the basis of the policy framework outlined in the next section.

\section{Semi-structured interviews}

Conducted between January and March 2019 in Riyadh and Jeddah, the semi-structured interviews $(\mathrm{n}=21)$ with displaced Syrians in Saudi Arabia provide an illustrative rather than a representative sample of the diversity within the displaced community in the Kingdom. The method was chosen primarily due to time and budget constraints allocated for fieldwork.

Table 1: Selected descriptive statistics of the interviewees

\begin{tabular}{cc}
\hline Category & Value \\
\hline Number of interviewees & 21 \\
\hline Age cohort (avg) & $30-40$ \\
\hline Gender (male) & 0.86 \\
\hline Legal status (iqama) & 0.71 \\
\hline Education (higher) & 0.64 \\
\hline Employment (yes) & 0.62 \\
\hline Family in KSA (yes) & 0.90 \\
\hline Arrival post-2011 (yes) & 0.48 \\
\hline
\end{tabular}

The interview sampling strategy was non-probability sampling to obtain access to the community of displaced Syrians within Saudi Arabia. In particular, self-selection, convenience, and snowball sampling methods were used to recruit interviewees throughout the three months (please see Appendix - Figure 2).

While the sample used is not representative due to the absence of probability sampling as a strategy, time and resource limitations prevented greater access to a list of Syrian residents in Saudi Arabia from which interviewees could be drawn. Out of the 21 Syrian community members who participated in semi-structured interviews, the average age ranged between 30 and 40 years. More than half of interviewees had completed high school education and were employed, and the majority has at least one other family member in Saudi Arabia at the time of the interview. The sample was almost evenly divided among those who arrived pre- and post-2011, a year that marked the onset of the war in Syria. Almost all interviews were conducted in Arabic.

When necessary, the interviews were conducted in both English and Arabic. Subsequently, all interviews were transcribed and translated into English for analysis purposes. As an overarching strategy, social media, personal contacts, and already established links were used to reach out to more potential interviewees.

\section{Results}

Despite being a non-signatory of the 1951 Convention and the 1967 Protocol, Saudi Arabia has been receiving and accommodating a large number of displaced populations in the past half a century. These communities include both Arab and non-Arab groups, some of whom had the opportunity to naturalise and eventually obtain Saudi citizenship. In addition to Islamic 
jurisprudence, the policies created for each group make the foundation of the Saudi concept of asylum and, subsequently, inform the Saudi approach to reception and accommodation of displaced Syrians post-2011 (Osmandzikovic, 2019b).

In recent history, the most unique example of refugee reception in the Kingdom occurred in the 1990s. After the Gulf War in 1991, more than 23,000 Iraqi civilians fled to Saudi Arabia and were placed in Rafha camp, located around $12 \mathrm{~km}$ from the Iraqi-Saudi border. In an agreement with the UNHCR, Saudi Arabia recognised displaced Iraqis as refugees on 5 August 1991. At the end of 1992 , the number of refugees in the Rafha refugee camp rose to 33,200 .

Table 2: Brief historical snapshot of displaced communities in Saudi Arabia

\begin{tabular}{ccccccc}
\hline Community & Number & Year(s) & Crisis cause & $\begin{array}{c}\text { UNHCR } \\
\text { assistance } \\
\text { and } \\
\text { registration }\end{array}$ & $\begin{array}{c}\text { Type of } \\
\text { accommodation }\end{array}$ & $\begin{array}{c}\text { Primary } \\
\text { outcome }\end{array}$ \\
\hline Uighurs & 50,000 & $1930-50$ & $\begin{array}{c}\text { Communist } \\
\text { persecution }\end{array}$ & No & Urban (Mecca) & Citizenship \\
\hline Iraqis & 33,200 & 1991 & Gulf War & Yes & Camp (Rafha) & Repatriation \\
\hline Palestinians & 240,000 & 2001 & $\begin{array}{c}\text { Second } \\
\text { Intifada }\end{array}$ & Yes & Urban (various) & Residence \\
\hline
\end{tabular}

In liaison with the UNHCR, the provision of assistance to Iraqi refugees by the Kingdom made this type of assistance reach a high level unmatched on a global scale at the time (please refer to table 3).

Table 3: Breakdown of service provision by the government in Rafha camp for Iraqi refugees

\begin{tabular}{cl}
\hline \multirow{2}{*}{ Nutrition } & $\begin{array}{l}\text { Each refugee had a variety of food including: bread, fresh fruit, sweets, melons, fish, } \\
\text { rice, flour, pasta, red meat, chicken, fresh vegetables, cheese, potatoes, olives, beans, } \\
\text { jam, dry milk, dates, lentils, seasonal dates, eggs, etc. }\end{array}$ \\
\hline \multirow{3}{*}{ Water } & $\begin{array}{l}\text { Each house had a running tap in the family section. The singles section was equipped } \\
\text { with shared water taps. In addition, camp officials provided 240,000 liters of water } \\
\text { per day, equivalent to } 14 \text { liters of drinking water per person per day. }\end{array}$ \\
\hline \multirow{3}{*}{ Healthcare } & $\begin{array}{l}\text { A state-of-the-art hospital was built at a cost of } 100 \text { million Saudi Riyals in } 1993 \text { at } \\
\text { the site, in which } 27 \text { doctors and } 40 \text { nurses provided healthcare services to refugees. } \\
\text { In addition to the camp hospital, five doctors worked in the women's primary clinic } \\
\text { in the family section and the primary men's clinic inside the camp. All medicines } \\
\text { prescribed by doctors were free of charge. }\end{array}$ \\
\hline & $\begin{array}{l}\text { Waste was collected by } 7 \text { trucks a day, except on Fridays. There were also many } \\
\text { disposal boxes distributed in appropriate places across the camp. Around 212 Iraqi } \\
\text { refugees worked as cleaners in the camp and were paid financial rewards for their } \\
\text { services. }\end{array}$ \\
\hline \multirow{2}{*}{ Education health } & $\begin{array}{l}\text { The number of classrooms in the camp school totaled at 111. The total number of } \\
\text { students was 2,840. The Saudi government appointed Iraqi refugee teachers for } \\
\text { education to be paid financial rewards. }\end{array}$ \\
\hline Clothes & $\begin{array}{l}\text { A clothing allowance was made twice a year, 350 Saudi Riyals for women, 300 Saudi } \\
\text { Riyals for men, and 250 Saudi Riyals for children. }\end{array}$ \\
\hline
\end{tabular}


This type of assistance, however, failed to generate self-sustainability. The problem remained with the nature of the Rafha refugee camp, given its curfew hours and absence of viable employment opportunities, all of which largely made the displaced Iraqis dependent on government assistance and incapable of self-reliance.

Given the vagueness of the 1992 Declaration [UN 1992] and the 1994 Arab Convention [UN 1994], the contemporary Saudi approach to the integration of displaced Syrians is not particularly drawn from neither of the two documents. As much as the member states of the European Union were caught off guard with the European refugee crisis in 2015, the member states of the Arab League had been equally unprepared to cope with the Syrian refugee crisis only a few years prior to that.

On the regional level, the most alarming aspect of the Syrian refugee crisis in the Arab world is its continued mismanagement. The contemporary initiatives relating to the refugee questions do not reflect the 1992 Declaration and the 1994 Convention across the Arab world, wherein many countries continue to struggle with their refugee populations, except Saudi Arabia.

With that experience and the vague language of the 1994 Arab Convention, Saudi Arabia faced the Syrian refugee crisis in 2011 without a concrete blueprint. However, the Kingdom has responded to the crisis by devising an alternative approach to reception and accommodation of displaced populations, subsequently applying the same principles to displaced Yemenis with the onset of war in Yemen in 2015.

\section{The alternative approach}

The Saudi approach to reception and accommodation of displaced Syrians started with a series of Royal Decrees and High Orders issued during the early years (2011-2014) of the conflict in Syria. These orders set the basis for legal status regularisation, employment, healthcare, education, and social integration. Based on these documents, a mechanism was put in place for the indefinite renewal of visit visas for displaced Syrians (Osmandzikovic, 2019b).

With the start of the conflict in Yemen, those fleeing the violence in that country were given indefinite visit visas. Several thousands of them remain in the southern part of the Kingdom, thus demonstrating flexibility, the on-ground developments, and the magnitude of the crisis. Since 2011, Saudi Arabia has developed a comprehensive approach to the integration of displaced Syrians.

The Saudi approach rests on five core pillars: (i) legal status regulation, (ii) access to education, (iii) access to healthcare, (iv) access to the labour market, and (v) social integration (Osmandzikovic, 2019b). At its core, it applies the traditional understanding of the visitor status to accommodate displaced Syrians within the existing socio-economic structure of the country, tailored to both nationals and non-nationals.

Since 2011, displaced Syrians have come to Saudi Arabia post-2011 on a visit visa and are officially referred to as Syrian visitors. With 31 December 2018, 673,669 Syrian visitors were residing in the Kingdom, with the number of 2,570,972 visit visa renewals from 2011 until the beginning of 2019 (please see Appendix-Fig. 3).

Adaptive nature and comprehensive cross-field coverage distinguish the program for Syrians from other programmes (Osmandzikovic, 2019b). The programme started with Royal Decrees and High Orders issued between 2011 and 2015, setting the foundation for subsequent legal status 
regularisation, employment, healthcare, education, and social security. The mechanism of indefinite renewal of visit visas for displaced Syrians was put in place immediately in 2011 with the onset of the war in Syria. The over-stayers have been continuously exempted from fines and deportation, a measure that subsequently included Yemenis.

\section{Healthcare and charity organisations}

The government has enabled access to government hospitals for displaced Syrians free of charge without a requirement of health insurance, a measure that is usually not available to other non-nationals.

Table 4: King Salman Humanitarian Aid and Relief Centre annual report 2014-2015

\begin{tabular}{ccc}
\hline Programme name & Number of beneficiaries & Total budget (USD) \\
\hline $\begin{array}{c}\text { Medical service provided to Syrian } \\
\text { visitors/refugees in public hospitals }\end{array}$ & 35,232 & $93,928,512$ \\
\hline $\begin{array}{c}\text { Medical service provided to Syrian } \\
\text { visitors/refugees in primary healthcare centers }\end{array}$ & 369,346 & $147,738,400$ \\
\hline
\end{tabular}

Table 5: Yearly breakdown of the number of displaced Syrians in Riyadh assisted by one charity

\begin{tabular}{cccccc}
\hline Year & 2014 & 2015 & 2016 & 2017 & 2018 \\
\hline Total Number of Syrian visitors treated & 95 & 100 & 112 & 1,167 & 2,000 \\
\hline
\end{tabular}

Local charity organisations whose mandate was to assist nationals in the lower income bracket have assisted Syrians with irregular legal status and whose documents had expired, covering up to 70 per cent of their medical expenses in private hospitals. One charity alone assisted more than 3,500 displaced Syrians residing in Riyadh in the 2014-2018 period.

\section{Education}

The Saudi government has designed and implemented a scholarship programme for Syrians with a visit visa in public schools. Under this programme, a total of 141,604 Syrian children have been enrolled in public schools in the 2011-2018 period while more than 7,950 seats have been allocated to them in public universities. One of the most prominent examples of assistance to Syrian students in higher education has been the King Abdullah Scholarship programme that integrates the Syrian students, on a visitor visa or in possession of residency, into a larger scholarship scheme as part of the public university programme (King Salman Centre for Relief and Humanitarian Aid, 2016).

Table 6: King Salman Humanitarian Aid and Relief Centre annual report 2015-2016

\begin{tabular}{ccc}
\hline Programme name & Number of beneficiaries & Total budget (USD) \\
\hline $\begin{array}{c}\text { The Custodian of the Two Holy Mosques Higher } \\
\text { Education programme to assist Syrian students (one } \\
\text { academic year) }\end{array}$ & 7,950 & $105,997,350$ \\
\hline $\begin{array}{c}\text { Assistance to Syrian students enrolled in public } \\
\text { education (all educational levels) }\end{array}$ & 141,406 & $377,129,802$ \\
\hline
\end{tabular}


In a focus group with administration staff and three Syrian female students at the female campus of Dar Al Ulum (DAU), a private university in Riyadh, the themes of the discussion echoed the interview themes. It included the students' conflict background, life in the Kingdom, legal and socio-economic implications of displacement, students' long-term plans, and the administrative leniency by the university towards Syrian students.

The administration confirmed that they talk to Syrian students regularly and are aware of their sensitive situation. The students stated that life had gotten harder with each passing year. One of the hardest implications was that all three students had family members who have either died or have been directly harmed by the conflict in Syria. All three students described life in Saudi Arabia as normal as they live with other Syrians, locals, and other Arabs. They don't see themselves culturally or socially different to Saudis. Upon graduation, they plan to work in the Kingdom, as they see it as their home.

The programme caters to all levels of education even though it has not coped well with overcrowded public schools. In central parts of the city, the demand for education has not been fully met with the supply of vacant seats for Syrian children. In addition, private schools tend to be expensive and the government scholarship for Syrian children does not cover the private sector, thus making enrolment somewhat challenging.

\section{Employment}

The addition of access to the labour market, as a key pillar of the government programme for displaced Syrians in 2016, resulted in the development of a special program called Ajeer for Syrian and Yemeni visitors (Ministry of Labour and Social Development, 1994).

In light of the continued support for displaced populations, the Ministry of Labor and Social Development (MoL) has allowed displaced Syrians to obtain or renew temporary work permits via the Ajeer portal. The programme and the service are restricted to establishments, companies, and organisations registered with the Ministry and which are part of the ministry's database. Such organisations, companies, and establishments should have an active MoL account and fall into the medium green range and above ${ }^{2}$, providing that the establishment will not fall into lower ranges in the Nitaqat program because of hiring the visitor.

According to the ministry, when a temporary work permit is issued, the nationalisation rate of the hiring company is changed in the Nitaqat programme during the effective period. In other words, hiring employees, including displaced Syrians, through the 'Ajeer' program is beneficial for the hiring entities, given that the process alleviates their status in the overall Nitaqat system. Additionally, the establishment should register Syrian visitors with the General Organization for Social Insurance (GOSI), as their entry into the programme automatically provides the same workplace safety rights as the regular residency holders.

In the first three years since the creation of the programme, more than 14,000 work permits have been issued for Syrians on a visit visa. Overall, the program has shown to be fairly successful,

\footnotetext{
${ }^{2}$ In light of the nationalization of the workforce, the MoL Nitaqat program divides all organizations, companies and establishments in four categories. Namely, entities in the platinum category are constant outperformers in Saudization. Entities in the green category are divided into high, medium and low green, depending on how many Saudi nationals they hire. The other two ranges are yellow and red, the latter being the least satisfying.
} 
given that entry into the programme automatically provides labour law protection that is extended to all those on a work visa, including protection against physical harm at the workplace. The programme, however, only includes males, which leaves a substantive number of Syrians ineligible to obtain employment within the Kingdom.

Table 7: 'Ajeer' programme numbers for displaced Syrians in Saudi Arabia until March 2019

\begin{tabular}{ccccc}
\hline Category & 2016 & 2017 & 2018 & 2019 (until March) \\
\hline $\begin{array}{c}\text { Number of confirmation notices } \\
\text { issued for Syrian visitors }\end{array}$ & 5,354 & 5,003 & 3,361 & 575 \\
\hline $\begin{array}{c}\text { Number of Syrian visitors who } \\
\text { benefited from issued notices }\end{array}$ & 3,951 & 3,162 & 2,664 & 575 \\
\hline
\end{tabular}

\section{Topic modelling}

While topic modelling interviews conducted with displaced Syrians in Saudi Arabia, I use textual analysis based on word co-occurrences and topic modelling in $\mathrm{R}$ based on a fairly novel approach to qualitative data analysis (Welbers, Van Atteveldt, and Benoit, 2017).

Given the novelty of the approach to the perception of displaced populations on their reception and accommodation in a non-signatory country of the 1951 Refugee Convention and the 1967 Protocol, I conduct textual analysis based on word co-occurrences and topic modelling in R. Herein, I generate code for recognising the most commonly occurring patterns of words in interviews with displaced Syrians, subsequently clustering them around several software-identified themes, which is expanded on in the following sections of the article (please see Figure 4 in the Appendix for the code). The analysis excluded common words and phrases for higher accuracy.

In total, 21 individuals participated in semi-structured interviews. When necessary, the responses of the interviewees were transcribed from Arabic into English language and fed into the software for analysis. The five themes which have emerged from the interviews are the following: (i) sense of displacement, (ii) family and uncertainty, (iii) social integration, (iv) legal status regulation, and (v) education and children. When juxtaposed to official policies designed by the government of Saudi Arabia and outlined in the previous sections, the emerging interview themes closely align with the core aspects of the Saudi approach to reception and accommodation of displaced Syrians within the Kingdom.

The core areas of concern identified in the semi-structured interviews with displaced Syrians touch upon issues addressed by the government when designing policies to accommodate the group in question, including healthcare, legal status regulation, education, and employment. However, topic modelling of interviews with displaced Syrians also suggests that displacement and subsequent integration into the host society is a highly subjective process, even in systems where displaced populations are not placed in camps and made dependent on external assistance. The following paragraphs outline selected interviews to further illustrate the software-generated cluster theme. 
Table 8: Results of topic modelling

\begin{tabular}{ccccc}
\hline $\begin{array}{c}\text { Sense of } \\
\text { displacement }\end{array}$ & $\begin{array}{c}\text { Family and } \\
\text { uncertainty }\end{array}$ & Social integration & $\begin{array}{c}\text { Legal status } \\
\text { regulation }\end{array}$ & $\begin{array}{c}\text { Education and } \\
\text { children }\end{array}$ \\
\hline Saudi & work & Syrian & visit & children \\
\hline remain & family & family & Riyal & school \\
\hline wife & life & Saudi & visa & Riyadh \\
\hline back & health & back & month & private \\
\hline Syrian & money & home & pay & enroll \\
\hline 2011 & apart & live & year & acceptance \\
\hline husband & hard & time & Iqama (residency) & services \\
\hline expenses & live & situation & obtain & university \\
\hline Arab & difficult & assistance & renew & program \\
\hline future & issues & Aleppo & status & start \\
\hline
\end{tabular}

\section{Theme 1 - Sense of displacement}

The first theme encompasses disrupted family ties and the chaos-like nature of the conflict in Syria, with the emphasis on 2015 and 'future', 'back', 'remain [in Saudi Arabia]', and '[living] expenses'. The first theme illustrates the subjective notion of ghurba, which, in a literal sense, signifies separation and is typically used to refer to the state of being a foreigner away from one's country or community of origin. It evokes the simultaneous and conflicting processes of yearning and estrangement (Risse, 2019). One male interviewee from Manbij, north-eastern Syria:

"I finished my studies at the University of Aleppo, where I later got a job at the university and got married to my college sweetheart. Together with me, she worked as a teacher and a scholar as well. The war disrupted everything. We had a family and four children, a good life, summer vacations. (...) I came to [Saudi Arabia] in 2012 from Manbij, and I spent the first year and a half looking for a job. (...) Together with our children, my wife fled to Turkey once the Islamic State took over our house. She had some family in Turkey, so they were not completely alone. After some six months, they came to join me [in Saudi Arabia]. It took me a very long time to switch from a visit visa to 'iqama' - residency. My wife remains without a job. Since 2011, we got four more kids, and I have to work two jobs to provide my family with a decent life, but nothing can compare to what we used to have back home."

One female interviewee from Damascus:

"I have been [in Saudi Arabia] since2011 with two of my sons. My third son is in the United States with his wife and children, having gone to Saudi Arabia, then Egypt, and finally settling in the US, just like my sister and her children. (...) I do not feel happy at all. I cannot see one of my four sons. He is in Egypt, in his thirties, without a job. He has no health insurance and no stable income despite having many health issues. I am unable to care for him. I want to bring him to Saudi Arabia, but it is impossible. (...) I heard many complaints from elderly [Syrian] women, and they are all the same, more or less. Many have scattered families that they cannot see, just like myself. Many cannot send their children back to Syria because they are afraid their children might be forced 
into the army. Many have unemployed children who struggle to survive and stay legal. It's tough for everyone who is forced to leave their country."

\section{Theme 2 - Family and uncertainty}

The second theme puts a larger emphasis on safeguarding the family's security through stable employment, with a special focus on 'work', 'health', 'life' and 'money'. Within the second theme, interviewees grapple with the everyday challenges of life in displacement, employment issues, and the practical dissonance between their previous employment in Syria and the current one at the time of the interview in Saudi Arabia. One male interviewee from Aleppo:

"The immediate couple of years after 2011 were the most difficult ones for my family. This has slowly been getting better in recent years, I was able to travel back home and see my family. I am still alone [in Saudi Arabia] and they are back in Syria. (...) Some of my [extended] family members are in Turkey, Lebanon, Jordan, and Europe. I have no one with me [in Saudi Arabia]. Many [refugees] have returned to Aleppo from Jordan and Lebanon, at least 50 percent, according to the stories I have heard. And I try to stay in regular contact with people from my community back home. (...) I am uncertain about my future, mostly because I am [in Saudi Arabia] without my [immediate] family but as long as I have stable income and means to support my family, I can't complain."

One male interviewee from Damascus:

"I work as a regional manager for my company and I earn a good salary. I had to work hard for many years to get to where I am, even though I am relatively young. Thank God, I can support my extended family, including some of my brothers and cousins who are not as fortunate. I also regularly donate and try to give to anyone I can in the Syrian community here [in Saudi Arabia]. I have an apartment in Jeddah and an apartment in Riyadh. I also have a car in Riyadh. I was able to get my family to join me [in Saudi Arabia] very early on. My wife and our two kids are with me, and my mom recently joined us. Life is not too difficult but I think it was easier to live [in Saudi Arabia] some 10 years ago. Now, it's hard for everyone across the board, Saudi or non-Saudi. (...) I am from Damascus and my house in Damascus is safe. It wasn't damaged because I asked relatives to take care of it, but I do not plan on going back any time soon, as I would be recruited in the army, even though I did my military service well before the war started. I have a good job [in Saudi Arabia] and my family is here with me. I feel grateful and blessed."

\section{Theme 3 - Social integration}

The third theme touches upon social integration in the Kingdom through 'back', 'home', 'live', 'situation', 'assistance', and the juxtaposition of 'Syrian' and 'Saudi'. This theme also illustrates the interaction of the displaced Syrian community with the local Saudi population. The Syrian community in Saudi Arabia has a long history of existence and socio-economic exchange with the Saudi population that predates the 2011 Syrian war. However, such a relationship has morphed and changed after 2011 with the large-scale arrival of displaced Syrians, hence changing the makeup of pre-war Syrian residents in the Kingdom. Syrians who arrived in Saudi Arabia after 2011 maintain an overall sense of separation from the local Saudi population, which is exemplified in selected interviews below. One male interviewee from Raqqa: 
"I currently work at a [Syrian] restaurant in the kitchen. I am a chef by calling and I worked as a chef back in Syria for many years. After coming here [to Saudi Arabia] with my family, I immediately applied for a visa to the United States, Canada, and Europe through the countries' embassies but I always got rejected, so I stayed. My family is here with me and we live above the restaurant on the same floor with a couple of other families [from Syria]. My children are small and one of them is a baby; I need to take care of them anyway I can. I work and feed my family and my wife stays with the children because they are still too young for school. We don't have much, but we also don't need much. I have been [in Saudi Arabia] for six years now. I have an 'iqama' residency - and I can work legally but my entire [immediate] family is on a visit visa. Overall, I would say that there is a lot of work here [in Saudi Arabia] for those who want to work. (...) I have had a good relationship with Saudis from the very beginning. I never felt discriminated or not welcome. I never had issues and neither has my family. But I have to say that I live and work with Syrians in a neighbourhood with a lot of Syrians, many of whom come from my neighbourhood in Raqqa, so there isn't much interaction [with the local population] daily. But I have to say that Saudis gladly come to the restaurant and love Syrian food."

One female interviewee from Manbij:

"Most Syrians I know [in Saudi Arabia] are from Raqqa, Deir Ezzor, and Aleppo. When I want to go to a doctor, I know what Syrian doctor to go to [in Saudi Arabia]. Syrian doctors are well known within the community since many had already been established in the Saudi society as medical experts before the conflict. When I want to fix my teeth, I know what Syrian dentist to go to [in Saudi Arabia]. (...) Also, most Syrians know most other Syrians, as our community tries to keep in touch, even if it's not in person. If someone dies, we all send messages on Facebook, if we can't attend the funeral. We also collect money for the family of the deceased if they need some assistance to get back on their feet, especially if the husband dies and the wife is left alone. The news spread fast among the community since, sometimes, that's the only way to stay together and hear news from back home. (...) I am more in touch with Syrians than with Saudis, but I have not had bad experiences personally. I spend most of my time with my family anyway. (...) Some Syrians might want to flee to Europe, but not me. I think Saudi Arabia is better because it's at least Islamic and at least Arab. I don't want Europe."

One male interviewee who is originally from Damascus but has resided in Saudi Arabia prior to the conflict onset in 2011:

"I work as a delivery guy and the discrimination I face is hard to cope with, especially on a daily basis. I am sometimes harassed at work. If I am tired, they tell me to go back to Syria. On the streets, if I mention I am Syrian, people tell me to go home and ask why I'm taking their jobs. Even the [Saudi] friends I grew up with don't fully understand my struggle, even though they are kind to me. (...) Even though I have been raised [in Saudi Arabia], people call me 'ajnabi' - a foreigner. But I feel I am also from this country since my entire life has been based here. I don't remember my life in Syria and I don't think I will ever go back to live there, even after the conflict ends. So, it's quite difficult for me to navigate my life." 


\section{Theme 4 - Legal status regulation}

The fourth theme encapsulates legal status regulation or the legality of stay in Saudi Arabia with words such as 'visa', 'month', 'pay', 'renew', and 'iqama'- residency. It covers the implications of obtaining and maintaining legality within the confines of displacement and uncertainty, despite official guarantees and special legal provisions for displaced Syrians, and later displaced Yemenis, in regulating their status and stay in the Kingdom. One male interviewee from Damascus:

"I have the 'iqama' - residency. And I was able to get a stable job with a stable income. I work 10-12 hours every day, but I can't complain. I have my apartment and I host my mom who is on a visit visa. I take care of her since I am sponsoring her to stay [in Saudi Arabia]. I cannot go back to Syria because I will be taken into the army even though I served the mandatory conscription before the war. My age is a problem so I can't go back for a very long time. I am single, yes, because I do not earn enough money to get married. But as long as there is work, I have to be content and grateful. I'm quite grateful for the opportunities given to me [in Saudi Arabia] because many are not so lucky. (. . .) I don't think about the future. Perhaps I don't see myself [in Saudi Arabia] in the long run, but I definitely don't see myself in Syria either. (...) Overall, I try to run a very simple life and respect my obligations toward the country I am."

\section{Theme 5 - Education and children}

Lastly, the fifth theme circles around education and children, with the emphasis on 'enrolment', 'public', 'private' and 'acceptance'. The Saudi government has designed and implemented a scholarship program in public schools for Syrians with a visit visa, resulting in 141,604 Syrians children being enrolled in public schools from 2011 to 2018 and more than 7,950 seats allocated to them free of charge in public universities in the past seven years.

Overall, the program caters to all educational levels. However, it has not coped up well with overcrowded public schools, especially in the central city areas, which have not been able to fully meet the education demands for Syrian children. As an alternative, also discussed in the interviews, private schools tend to be expensive and the government scholarship does not cover the private sector [Osmandzikovic 2019b]. One male interviewee from Aleppo:

"I have seven children; two are in a private school and two are in a public school. Others are too young for school. Public schools, up until recently, accepted those who are on a visit visa as well, which was fantastic for my family, as we cannot afford private schools. While I personally haven't had any problems with the education system here, I have heard from other Syrians [within Saudi Arabia] that a number of Syrian children remain out of school, and I am unsure why."

Another interviewee from Manbij:

"The situation with Syrians in regard to education is mixed, I would say. I have eight kids, three of whom are old enough to attend school. They are currently enrolled in a private Turkish school and their classes are held in the Turkish language, as the school accepted those on a visit visa as well. This is extremely expensive for me, even though I am employed. But I have no other option. Previously, I tried enrolling [my children] in a public Saudi school, but it was difficult and the process took time, eventually did 
not happen. (...) I can't say that the Turkish curriculum is bad, but my children are being teased for being Arab by other children, which affects their self-confidence. I have to talk to them about their own identity and it's hard."

\section{Congruences and dissimilarities between official programming and the themes}

The above-mentioned five themes encapsulate the commonalities and nuances between each of the 21 interviewees, illustrating a juxtaposition with the official government policies put in place towards displaced Syrians since 2011.

However, the interviewees' responses, comments, and grievances have been primarily split based on employment. This was necessary as the legal status; namely, iqama, and health insurance, are based on one's employment status within the Kingdom. Syrians that were employed at the time of the interviews had a much better socio-economic and overall integration experience, on average than those who were not in employment.

The differences in the male and female experiences of displacement differed. None of the women I interviewed were employed at the time of the interview. All of them were on a visit visa sponsored by the male head of the family, and most with a primary role of caring for the family from within the household.

Overall, female interviewees had a more positive outlook on their integration experience in the Kingdom and their family prospects, on average, than male interviewees. All female interviewees in my sample were unemployed, two-thirds of them were housewives and one-third of students. This also related to the Ajeer programme's mandate only encompassing men, which might be a potential point of improvement for the future.

The general practice and the dynamics of the interviews conducted with Syrian women were completed within a family setting in the house with children, and sometimes the husband present in the room as well. Herein, some literature suggests that the interview setting has a significant influence on the interviewee's response and the overall interview. Moreover, I have to acknowledge the potential bias of my own cultural background [West and Blom 2017]. As I am unable to test for these effects. I state earlier that the interviews I conducted are illustrative rather than representative of the entirety of the population of displaced Syrians in the Kingdom of Saudi Arabia.

Further, Syrians who came to the Kingdom in the post-2011 period reported a much more positive experience, on average, than Syrians who had been born in the Kingdom or who had come earlier on. This demonstrates that the Saudi programme of assistance, in addition to helping displaced Syrians, also elevated the status of Syrians within the Saudi society, especially in the post2011 period. In relation to employment in particular, the earlier-mentioned Ajeer programme for Syrian and Yemeni visitors has been founded on the unique legal status of displaced Syrians within the Kingdom in order to provide them with the necessary and government-led transition into a more regularised labour market within the country. None of the interviewees, however, were beneficiaries of the programme.

In regard to generational differences, younger Syrians tended to have a more negative overview of their integration experience with a bleaker outlook on the future, on average, when compared to older Syrians. This might be correlated with employment, given that those in the lower age bracket 
tended to also be unemployed or in a low-income position, compared to those in the higher age bracket.

\section{Discussion and conclusion}

As a comprehensive programme, the Saudi approach to the integration of displaced populations has demonstrated a wide area of coverage, flexibility, and adaptability in the wake of external crises. At its core, the approach covers legal status, education, healthcare, employment, and social integration. With the onset of war in Yemen, the approach has shown to apply to displaced Yemenis as well, thus demonstrating that it is not exclusive to a particular group of displaced persons. Further, with the development of the Ajeer programme for employing displaced Syrians, and later Yemenis, the approach has also shown flexibility and ability to adapt to the demands of the country's domestic labour market and bridge it with the visitor status of displaced Syrians (Ministry of Labour and Social Development, 1994).

The overall collapse of the traditional relationship between displaced populations and their host-countries begs a novel approach toward accommodation and eventual integration, thus reconciling the host-countries' geo-economic interests with the needs of the displaced populations, especially in countries that are not signatories to the 1951 Refugee Convention and the 1967 Protocol. As a non-signatory, Saudi Arabia has organically developed a novel approach to the reception and accommodation of displaced Syrians, wherein it has demonstrated a wide area of coverage, flexibility, and adaptability in the wake of external crises.

As Betts and Collier state in their research (2015), displaced populations need autonomy and opportunity in their host-countries, which only integration into the economy can provide. Saudi Arabia has attempted to utilise a novel approach to socially and economically accommodating displaced Syrians, later applying the same principles, albeit in a slightly morphed manner, to displaced Yemenis in the post-2015 period, in order to galvanise self-sustainability.

In order for the Saudi approach to translate into self-sustainable policies with a long-term vision, there needs to be some avenues of further improvement. These include a: (i) clarification of the categories of beneficiaries, (ii) enhanced communication both horizontally among the coordinating government bodies and vertically between the government and the general public, (iii) coordinating body to oversee monitoring and conduct follow-up on specific provisions of the programme, and (iv) transformation of the special legal provisions for visitors into a form of a protected status, thus distinguishing them from regular visitors and embedding the approach within a nationwide response mechanism for future refugee crises, thus addressing the issues outlined in the interviewees' testimonies in the previous section.

All of these recommendations require a unified data source, which would reside with a coordinating body. In addition, all of these recommendations also require deeper collaboration between the government entities and civil society organisations in order to bridge the gap between high-level policies and on-ground realities. In addition to ensuring self-sustainability of the approach, in the long run, the recommendations will warrant that the approach passes the test of diversity, in the sense that it can be applied to any group displaced persons in the future. The approach provides a concrete example of a comprehensive and flexible programme that can be further enriched with data. 
Given that Saudi Arabia is host to the largest number of displaced populations in the Gulf Cooperation Countries ${ }^{3}$, the Kingdom's approach to reception and accommodation of displaced Syrians may serve as a blueprint for other countries. With the Syrian refugee crisis, the international community has tried to solve the inadequacies of the traditional approach to reception and accommodation of displaced populations, which is demonstrated with the recent shift towards a development-centred approach under the New York Declaration (2016) and the subsequent Compact, thus alleviating the primary responsibility of United Nations High Commissioner for Refugees.

However, traditional immigration systems of individual host countries have struggled to keep pace. With the help of the New York Declaration and the subsequent Compact, context-specific approaches to reception and accommodation of displaced populations, such as the approach of Saudi Arabia, can be scaled up to the signatories as well, thus assisting them in the way forward.

\section{References}

Aleinikoff, A. (2015). From Dependence to Self-Reliance: Changing the Paradigm in Protracted Refugee Situations. Report. Migration Policy Institute. doi: https://www.migrationpolicy.org/research/dependence-self-reliance-changing -paradigm-protracted-refugee-situations.

Arnaout, G. M. (1986). L'asile dans la Tradition Arabo-Islamique. Geneva, Switzerland: United Nations High Commissioner for Refugees.

Bakker, L., J. Dagevos, and G. Engbersen (2014). "The Importance of Resources and Security in the Socio-Economic Integration of Refugees. A Study on the Impact of Length of Stay in Asylum Accommodation and Residence Status on Socio-Economic Integration for the Four Largest Refugee Groups in the Netherlands". International Migration and Integration, pp. 431-448. doi: https: //doi.org/10.1007/s12134-013-0296-2.

Bansak, K. et al. (2018). Improving refugee integration through data-driven algorithmic assignment. Report. doi: 10.1126/science.aao4408. Barou, Jacques (2014). "Integration of immigrants in France: A historical perspective". Identities: Global Studies in Culture and Power. Vol 21, pp. 642-657.

Betts, A. and P. Collier (2015). Help Refugees Help Themselves. Web Page. [date accessed: 2020-02-02]. URL: https: / / www. foreignaffairs .com / articles/levant/2015-10-20/help-refugees-help-themselves.

Bevelander, P. and C. Lundh (2007). Employment Integration of Refugees: The Influence of Local Factors on Refugee Job Opportunities in Sweden. Discussion Paper N. 2551. doi: https://ssrn.com/abstract=958714.

Bloch, A. (2008). "Refugees in the UK Labour Market: The Conflict between Economic Integration and Policy-Led Labour Market Restriction”. Journal of Social Policy. Vol 37, pp. 21-36. doi: doi:10.1017/S004727940700147X.

Carens, J. (2005). "The Integration of Immigrants". Journal of Moral Philosophy, pp. 29-46. Castles, Stephen (2013). Age of Migration: International Population Movements in the Modern World. 5th edition. New York, NY: Guilford Press. CoEU (1990). The Dublin Convention. Council of the European Union - Legal Rule. [date accessed: 2018-0202]. url: https://eur-lex.europa.eu/legal-content/EN/TXT/PDF/?uri=CELEX:41997A0819(01)\&from=EN.

Dancygier, R. M. and D. D. Laitin (2014). "Immigration into Europe: Eco- nomic Discrimination, Violence, Public Policy". Annual Review of Political Science, Vol 17.1, pp. 43-64.

Dimitrov, A. and G. Angelov (2017). "Refugee Integration in the EU: Challenges and Economic Impact". Journal of Economic Alternatives, pp. 584-600.

Gonzales-Ferrer, A. et al. (2018). "Mixed marriages between immigrants and natives in Spain: The gendered effect of marriage market constraints." Demographic Research, Vol 39, pp. 1-32. doi: https://www.doi.org/10.4054/DemRes .2018.39.1.

Hainmueller, J., D. Hangartner, and G. Peitrantuono (2015). "Naturalisation fosters immigrant integration." Proceedings of the National Academy of Sciences, Vol 112, pp. 12651-12656. doi: 10.1073/pnas.1418794112.

Harvey, P. and J. Lind (2005). Dependency and humanitarian relief: A critical analysis. Research Report. Human Policy Group. doi: https://www.odi.org/sites/odi.org.uk/files/odi-assets/publications-opinion-files/ 277.pdf. Holmes, Seth

\footnotetext{
${ }^{3}$ Member States include: Bahrain, Kuwait, Oman, Qatar, Saudi Arabia, and the United Arab Emirates.
}

Copyright @ 2020 BORDER CROSSING 


\section{Integration of Displaced Syrians in Saudi Arabia}

M. and Heide Castaneda (2016). "The 2015 Refugee Crisis in Europe: Forum Representing the "European refugee crisis" in Germany and beyond: Deservingness and difference, life and death". Journal of the American Ethnological Society, Vol 43 (1), pp. 12-24. doi: https://doi.org/10.1111/amet.12259.

Huddleston, T., J. Niessen, and J. D. Tjaden (2012). Using EU Indicators of Immigrant Integration. Migration Policy Group - Report. Migration Policy Group.

Hurmerinta-Peltomäki, L. and N. Nummela (2006). "Mixed methods in inter- national business research: A value-added perspective". Management International Review, Vol 46.4, pp. 439-459. doi: https://doi.org/10.1007/s11575-006 0100-z.

Jacobsen, K. (2002). "Can refugees benefit the state? refugee resources and African state-building". Journal of Modern African Studies, pp. 577-596. doi: https://doi.org/10.1017/s0022278x02004081.

KSRelief (2016). Annual Report. Report. [date accessed: 2020-02-02]. URL: https://www.ksreliefnews.com/wpcontent/uploads/2018/12/Annual-Report -2015-2016.pdf.

Mayblin, L. (2017). "Imagining asylum, governing asylum seekers: Complexity reduction and policy making in the UK Home Office". Migration Studies, pp. 1- 20. doi: https://doi.org/10.1093/migration/mnx060.

McKim, C. A. (2015). "The Value of Mixed Methods Research: A Mixed Methods Study". Journal of Mixed Methods Research, Vol 11.2, pp. 202-222. MoL (1994). Ajeer Program for Visitors. Website. [date accessed: 2020-02-02]. url: https://www.ajeer.com.sa/. OECD (2012). OECD Indicators of Immigrant Integration 2012. OECD - Report. [date accessed: 2018-02-02]. OECD. url: https://doi.org/10.1787/ 9789264171534-en.

Osmandzikovic, E. (2017). "Immigrants' Integration Experience in Seven EU Countries". NYUAD Journal of Social Sciences, pp. 1-26.

Osmandzikovic, E. (2019a). "Refugee Characteristics as a Game-Changer for Integration in Fortress Europe." European Scientific Journal, pp. 1857-7431.

Osmandzikovic, E. (2019b). "The Saudi Approach to Reception and Accommodation: The Case of Displaced Syrians". King Faisal Centre for Research and Islamic Studies, pp. 1-6.

Risse, M. (2019). "Ghurba at Home - Views from Oman". Conference Paper. UN (1992). Declaration on the Protection of Refugees and Displaced Persons in the Arab World. [date accessed: 2020-02-02]. url: https://www.refworld .org/docid/452675944.html.

Risse, M. (1994). Arab Convention on Regulating Status of Refugees in the Arab Countries. [date accessed: 2020-02-02]. url: https://www.refworld.org/ docid/4dd5123f2.html. - (2016).

New York Declaration for Refugees and Migrants. [date accessed: 2020-02-02]. url: https://www.unhcr.org/new-yorkdeclaration-for -refugees-and-migrants.html.

UNHCR (1951). Convention and Protocol on the Rights of Refugees. United Nations High Commissioner for Refugees Legal Rule. [date accessed: 2018-02-02]. url:http://www.unhcr.org/uk/3b66c2aa10.

UNHCR (2000). The State of the World's Refugees. United Nations High Commissioner for Refugees - Report. [date accessed: 2020-02-02]. url: http://www.unhcr.org/ 3ebf9bb10.pdf.

UNHCR (2019). Global Trends: Forced Displacement in 2018. Annual Report. United Nations High Commissioner for Refugees (UNHCR). doi: https://www.unhcr.org/ statistics/unhcrstats/5d08d7ee7/unhcr-global-trends-2018.html.

Valenta, M. and N. Bunar (2010). "State Assisted Integration: Refugee Integration Policies in Scandinavian Welfare States: the Swedish and Norwegian Experience". Journal of Refugee Studies, Vol 23 (4), pp. 463-483. doi: https: //doi.org/10.1093/jrs/feq028.

Valenta, M. and K. Thorshaug (2013). "Restrictions on Right to Work for Asylum Seekers: The Case of the Scandinavian Countries, Great Britain and the Netherlands." International Journal on Minority and Group Rights, Vol 20, pp. 459482. doi: https://doi.org/10.1163/15718115-02003006.

Von Buchwald, U. (1994). "Refugee dependency: Origins and consequences in A. J. Marsella, T. Bornemann, S. Ekblad, J. Orley (Eds.), Amidst peril and pain: The mental health and well-being of the world's refugees". American Psychological Association, pp. 229-237. doi: https://doi.org/10.1037/10147-011.

Welbers, K., W. Van Atteveldt, and K. Benoit (2017). "Text Analysis in R, Communication Methods and Measures". Communication Methods and Measures, Vol 11, pp. 245-165. doi: https://doi.org/10.1080/19312458.2017.1387238.

West, B. T. and A. G. Blom (2017). "Explaining Interviewer Effects: A Research Synthesis". Journal of Survey Statistics and Methodology, pp. 175-211. doi: https://doi.org/10.1093/jssam/smw024. 